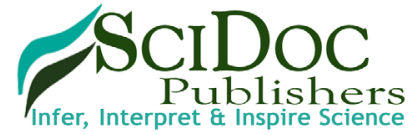

\section{An Appraisal Regarding Performance of ASHA in Rural Odisha-A Community Based Prospective Study}

\section{International Journal of Translation \& Community Medicine (IJTCM)} ISSN 2333-8385

Mishra $\mathrm{A}^{1^{*}}$, Mishra $\mathrm{K}^{2}$, Mohapatra $\mathrm{B}^{3}$

${ }^{1}$ Research Scientist, ICMR NTF-HI Project, AIIMS, Raipur, Chattissgarh, India.

${ }^{2}$ Associate Professor, Department of Community Medicine, SLN Medical College and Hospital, Koraput, Odisha, India.

${ }^{3}$ Dean and Professor, Department of Community Medicine, SLN Medical College and Hospital, Koraput, Odisha, India.

Abstract

The National Rural Health Mission (NRHM, 2005-12) now called National Health Mission (NHM) a flagship program of Government of India, has been launched since 12 years which it aims to deliver effective health care to the rural disadvantage population. Accredited Social Health Activist (ASHA) being the community health mobilizer is the main driving force of their area to the health system under NHM. This study aims to describe and relate factors affecting function of ASHA in her area, with a special focus on their service evaluation from various community stakeholders' perspective.

Aim of the Study: To describe various factors affecting performance of ASHA.

Material and Method: Community based cross sectional study design at Jagatsinghpur district in between July, 2012 to June, 2013 (12months). Convenient sampling procedure is being followed and total numbers of study respondents are 117. Predesigned pretested questionnaire is used for data collection.

Result and Discussion: Most of the (73\%) ASHAs are in service for financial reason. Eighty percent (80\%) of ASHA have adequate knowledge regarding Reproductive and Child Health (RCH) services. As per AWWs (Anganwadi Workers) opinion only $28 \%$ of the ASHA are good in referral of critical cases.

Conclusion: regular and periodic refreshing training should be given with assessment. Incentive rates should be revised in order to motivate them for better performance.

Keywords: NHM (National Health Mission); CHW (Community Health Worker); RCH (Reproductive and Child Health Services); PRI (Panchayat Raj Institutions).

\section{Introduction}

The National Rural Health Mission (NRHM, 2005-12) now called National Health Mission (NHM) a flagship program of Government of India, had launched since $12^{\text {th }}$ April, 2005 [1]. It aims to deliver effective health care to the rural population, especially the disadvantaged groups, by enhancing access, enabling community ownership and demand generation for assured quality services as per their need [2].

The concept of Community Health Worker (CHW) is not new, rather since past they are working in close association with the community health across many countries. A Cochrane review on health workers who worked amongst low-income communities of wealthy countries or amongst communities from developing countries shows evidence of CHWs' contribution to reducing child morbidity and mortality, increasing uptake of immunization and promoting good breast feeding practices [3, 4]. Another systematic review reports that CHWs in low-income countries (such as Bangladesh, Brazil and Nepal) have demonstrated the capacity to improve antenatal, perinatal and post-partum service utilization and to prevent perinatal and maternal deaths by early recognition and referral of complicated pregnancies [5-7].

In India the evolution of community worker may be summarized as follows. The Report of the Group on Medical Education and Support Manpower' popularly known as the "Srivastava Committee Report"(1975), proposes the CHW formally as a major part of the health system. In Gadchiroli Maharashtra, Society for Education, Action and Research in Community Health (SEARCH)

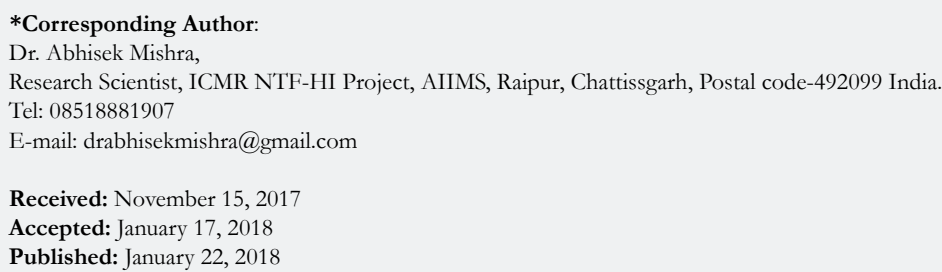

Copyright: Mishra $\mathbf{A}^{\circ}$ 2018. This is an open-access article distributed under the terms of the Creative Commons Attribution License, which permits unrestricted use, distribution and reproduction in any medium, provided the original author and source are credited. 
was established in 1986, Which first demonstrated how well home based neonatal care (HNBC) by community health volunteers could save child lives through early identification and antibiotic treatment for acute respiratory infections [8-10]. The Mitanin Program, introduced by the Government of Chhattisgarh in 2002 in which Women health workers were defined as community level care provider, facilitator and activists is another perfect example of CHW engagement with the health sector [11].

With these evidence based concepts about CHWs, the steering committee established National Rural Health Mission with a focus to create a band of female health volunteers, appropriately named "Accredited Social Health Activist" (ASHA) in each village within the identified States [12]. The term ASHA, whose meaning is "Hope" in English, was first mooted as an acronym for "Accredited Social Health Activist", but is now used as a specific term in itself [13-15].

A briefing about ASHA: As per Government of India guidelines the following are a few among many criteria that should be met by the women to serve as an ASHA. She is an incentive based worker who will create awareness on health, its social determinants and mobilize the community towards local health planning [16-18].

Other salient feature can be summarized as follows:

- ASHA must be primarily a woman resident of the village 'Married/Widow/ Divorced/Separated' and preferably in the age group of 25 to 45 yrs.

- ASHA should have effective communication skills, leadership qualities and be able to reach out to the community.

- ASHA should be a literate woman with formal education up to $8^{\text {th }}$ Class. Education qualification may be relaxed only, if no suitable person with this qualification is available.

- Adequate representation of disadvantaged population/ marginalized groups should be ensured to serve such population/ groups better.

The selection procedure of ASHA is being done by The District Health \& Family Welfare Society. The Society would designate Block Nodal Officers, preferably Block Medical Officers, to facilitate the selection process of ASHA. The Block Nodal Officer is supposed to constitute a Committee comprising 4-5 members of the local Village Health and Sanitation Commitment (i.e. Chairperson of the Committee (Woman Panch/Sarpanch), Aanganwadi Worker (AWWs), Auxiliary Nurse Midwives (ANW, now called Female Health Workers), School Teacher, existing ASHA (if any) and local ASHA Facilitators along with the District ASHA Coordinator (DAC), local Block ASHA Coordinator [19, 20].

Several evaluation studies have been conducted about the NHM program since its launch across different parts of India. Most evaluations are cross-sectional in nature, providing a snapshot of the ASHA at a particular time, with little ability to provide information on factors affecting effective functioning of ASHA, her community engagement skills, her role as a first level of contact with community to the existing health care system. Qualitative aspects like motivating factors for AHSA, client satisfaction from beneficiary perspective, perception of local leaders has not been evaluated through most of the research. Hence this study aims to describe the factors affecting the function of ASHA in her area, with a special focus on their service delivery evaluation from various community stakeholders' perspective in the Rural field practice area of Shreeram Chandra Bhanj Meidcal College and Hospital Cuttack, Odisha.

\section{Aim and Objective:}

1. To describe various factors related to performance of ASHA 2. To assess opinion of different stakeholders regarding functioning of ASHA

\section{Material and Methods}

Type of study-Cross sectional study design

Place of study-Naugaon Block of Jagatsinghpur district, Odisha Time of study-July 2012 to June 2013

Sampling-Jagatsinghpur district, the Rural Health And Training Center (RHTC) area of SCB Medical college is taken as study area. There are in total 8 blocks in this district. The block (Naugaon) having the lowest Institutional Delivery (64) in the last one year (2012-2013) has been taken for study purpose. One sector (Alanahat) is taken from this block by simple random method. All the 5 subcenters and 22 villages are taken for Study purpose from that block. One AHSA, One Angan Wadi Worker (AWW), One PRI (Panchyati Raj Institution) member and two beneficiaries from each of 22 villages are being interviewed (In Depth Interviews). At Subcenter level Health worker female (HWF) is being interviewed regarding the performance of ASHA. At Sector and Block level MO/Ic (Medical officer In charge) has opined their views about the working status of ASHA.

Qualitative research tools like focus group discussion (FGDs) and In depth interviews (IDIs) are being used for collection of response of different stake holders at different level.

Hence, in total 22 ASHA, 22 AWW, 22 PRI Members, 44 beneficiaries, 5 FHWs, 1 sector and 1 block Medical officers are being questioned. Hence, in total there are 117 persons being examined for the data collection.

The flow chart of data collection can be summarized as below:

The mode of research is by Combined, Quantitavie and Qualitative methods. Predesigned and pretested study questionnaire for different respondents are administered by the field investigator. Consent form has been signed after explaining the necessary information to each of respondent in local language. Those who have not willing to be in the study or not given the conscent are being excluded from the study. Medical officer of Sector and Block level have been interviewed by IDI (In depth interview) technique. There was periodic monitoring of the field activity by the guide in order to ensure adherence to the planned methodology as well as quality data collection. The collected data are being analyses by Microsoft excel and SPSS-16.

\section{Results and Discussion}

\section{Educational Status}

In this study as far as educational qualification is concerned 10 
Figure 1. Flow chart showing data collection.

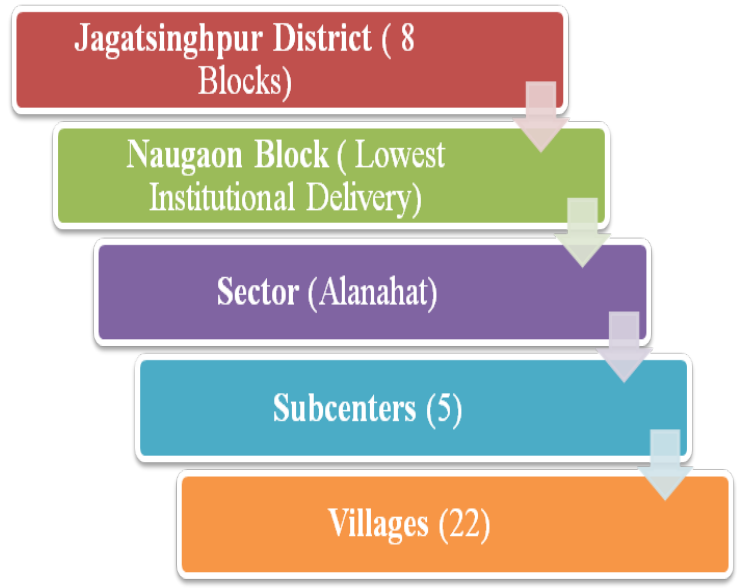

$(46 \%)$ have completed secondary class education, $7(32 \%)$ of them are educated up to higher secondary, only $4(18 \%)$ are educated up to the primary class. Only $1(4 \%)$ out of 22 ASHA is Graduate. One previous study conducted at Jagatsinghpur and Mayurbhanj District, Odisha in 2007-2008 has supported this finding and had shown that approximately half of the ASHAs have high school level education or more $(42.5 \%)$ [21, 22]. This study results supported by other research conducted by Ram Milan pasot et al., in 2012 at Luckhnow Uttarpradesh, which shows that among 400 ASHAs selected $30(7.5 \%)$ are graduate, $225(56.2 \%)$ are educated up to secondary school [23].

The reasons for joining as an incentive based community worker, is being assessed through questionnaires. Sixteen $(72 \%)$ of the ASHA has stated that they are currently working to support financially their family, none of them has joined the post with a purpose to serve the community. This finding is in the match with a previous report by Deoki Nandan et al., 2007, where the most important motivating factor ASHA for their job is to earn money as indicated by the majority $(71.3 \%)$ of the ASHAs. The second most important factor is the opportunity to serve the community $(33.8 \%)$ (16). Another study conducted by Hema Bhatt et al., 2012, shows the same finding that, most important influencing factor for joining ASHAs is monetary [24]. Hence lower educational level and poor motivating factor may together affecting poor performance of ASHA in this Block.

The knowledge of ASHA regarding Reproductive and Child Health (RCH) services, Maternal and Child Health services, Disease response and community mobilizing activity has been assessed in their study area. Regarding IFA (Iron and Folic Acid) Tablet consumption by pregnant mothers in their area is answered wrongly by $12(55 \%)$ ASHA. Similarly $10(46 \%)$ of them have demonstrated incorrectly the procedure of ORS (Oral Rehydration Suspension) preparation. This research is not in accordance with the finding that all ASHAs have full knowledge regarding JSY benefits as stated by Uttekar Bella Patel et al., 2008 [25].

The above figure describes the response of AnganWadi Worker's (AWWs) perception regarding the performance of ASHAs in their respective village. In their opinion all 22(100\%) of them are escorting the pregnant women for institutional delivery. $18(82 \%)$ ASHAs are helping people in getting Janani Surakhya Yojna benefit to the beneficiary. Most of the 20(91\%) ASHAs have attended all the immunization sessions in last 6 months, 2(9\%) ASHAs are absent in 1 or 2 immunization sessions in last 6 months. 11(50\%) ASHAs are mobilizing pregnant mother as well as children for immunization in the 2 blocks. Only 10 (45.4\%) ASHAs are doing the practice of reference of sick children in their territory according to AWWs view. According to AWW's 17(82\%) ASHAs are doing community mobilization work. This study supports the earlier study by Farah N. Fathima et al., 2015, in Karnataka state which reveals that regular house hold visit is being done by $86 \%$ of the ASHA, counselling of pregnant women regarding birth registration and Instiutional Delivery is being carried out with $88 \%$ of the ASHA in their study area [26].

The above figure depicts the response of Pachayat Raj Institution (PRI) Members towards the working status of ASHAs in their respective village. 20(91\%) PRI members have opined that ASHA was escorting pregnant women for institutional delivery. 15(68\%) PRI members have stated that ASHA is helpful to people in getting JSY benefit. 21(95\%) PRI members have opined that ASHA was doing the role of mobilizing the children towards fixed immunization sites. 11(50\%) PRI members have given their opinion that ASHA is involved in community mobilization work thoroughly in their respective working village. A research conducted by Farah N. Fathima et al 2015, in Karnataka state support the same finding that for Antenatal and Postnatal followups ASHAs are working excellent [26].

Among 44 (100\%) beneficiaries from the block 40 (91\%) had opined that ASHA has visited more than 3 times to their household during their antenatal period. 30 (86\%) beneficiaries had opined that ASHA has given them the advice to take IFA tablet in proper doses and 2 doses of TT vaccination during their pregnancy period.

Twelve $(32 \%)$ beneficiaries from the study area have opined that ASHA has not counseled them properly about institutional delivery. $30(68 \%)$ beneficiaries have stated in the manner that ASHA has helped them in getting Janani Surakhya Yojna (JSY) benefit. $40(91 \%)$ beneficiaries had stated that ASHA is present at the time of weighing the baby. From the study area, 39 (89\%) beneficiaries have told that ASHA has given them the advice regarding early initiation of Breast Feeding and Kangaroo Mother Care. 
Figure 2. Educational status of ASHA in selected Block.

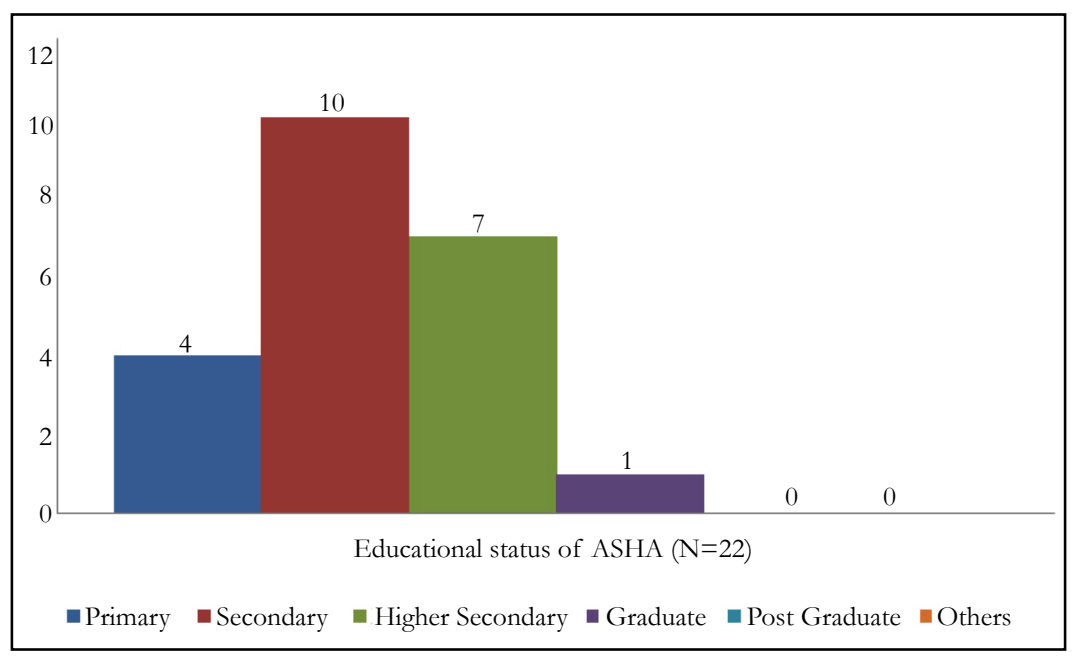

Table 1. Reason for opting to become ASHA $(\mathrm{N}=22)$.

\begin{tabular}{|c|c|c|c|}
\hline \multicolumn{2}{|c|}{ Reasons to be work as ASHA } & \multicolumn{2}{c|}{ Naugaon (N=22) } \\
\cline { 3 - 4 } & Financial Reason & Number & Percentage (\%) \\
\hline 1 & Hope for a Government Job & 4 & 72.7 \\
\hline 2 & Opportunity to seek knowledge & 2 & 18.2 \\
\hline 3 & With a purpose to Serve the community & 0 & 9.1 \\
\hline 4 & W & 4 & 0 \\
\hline
\end{tabular}

Table 2. Assessment of various component of functioning of ASHA (N=22).

\begin{tabular}{|c|c|c|c|}
\hline \multicolumn{4}{|c|}{ Naugaon Block $(\mathrm{N}=22)$} \\
\hline & & Number & Percentage \\
\hline \multicolumn{4}{|c|}{ Pregnancy \& outcome } \\
\hline \multirow{2}{*}{ Minimum ANC Checkup } & Correct & 17 & 77.3 \\
\hline & Incorrect & 5 & 22.7 \\
\hline \multirow{2}{*}{ Duration of IFA Tab. Intake } & Correct & 10 & 45.5 \\
\hline & Incorrect & 12 & 54.5 \\
\hline \multirow{2}{*}{ No. of TT Doses during Pregnancy } & Correct & 19 & 86.4 \\
\hline & Incorrect & 3 & 13.6 \\
\hline \multirow{2}{*}{ About Janani Surakshya Express } & Correct & 18 & 81.8 \\
\hline & Incorrect & 4 & 18.2 \\
\hline \multicolumn{4}{|c|}{ Child hood illness and response } \\
\hline \multirow{2}{*}{$\begin{array}{l}\text { Knowledge regarding management of a child } \\
\text { suffering from diarrhea }\end{array}$} & Correct & 17 & 77.3 \\
\hline & Incorrect & 5 & 22.7 \\
\hline \multirow{2}{*}{ Preparation of ORS } & Correct & 12 & 54.5 \\
\hline & Incorrect & 10 & 45.5 \\
\hline \multicolumn{4}{|c|}{ Community Mobilization Activity } \\
\hline \multirow{2}{*}{$\begin{array}{l}\text { Knowledge regarding mobilization of the } \\
\text { community }\end{array}$} & Correct & 17 & 68.2 \\
\hline & Incorrect & 5 & 31.8 \\
\hline
\end{tabular}

Qualitative data analysis about functioning of ASHA

The qualitative data analysis shows that ASHAs are most commonly understood as village health educators and link workers. ASHAs are seen as responsible for counseling and motivating women to complete antenatal care and hospital delivery. In our focus group discussion, ASHAs highlighted that:
We $[A S H A s]$ educate the community about diet, bygiene and sanitation. For example, use of clean clothes and regular change of napkins to prevent infections after delivery (FGD, ASHA).

We [ASHAs] are like a bridge between the community and hospital. Since doctors cannot visit all the places, if the need arises, we always escort mothers 
Figure 3. Perception of AWW about ASHA in their respective village.

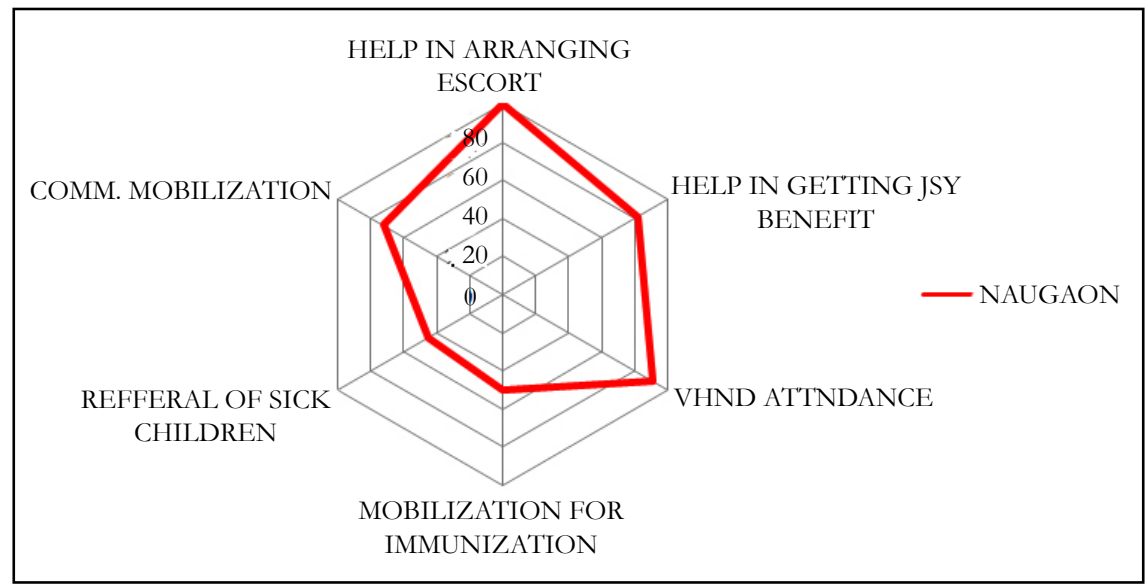

Figure 4. Perception of PRI members about ASHA.

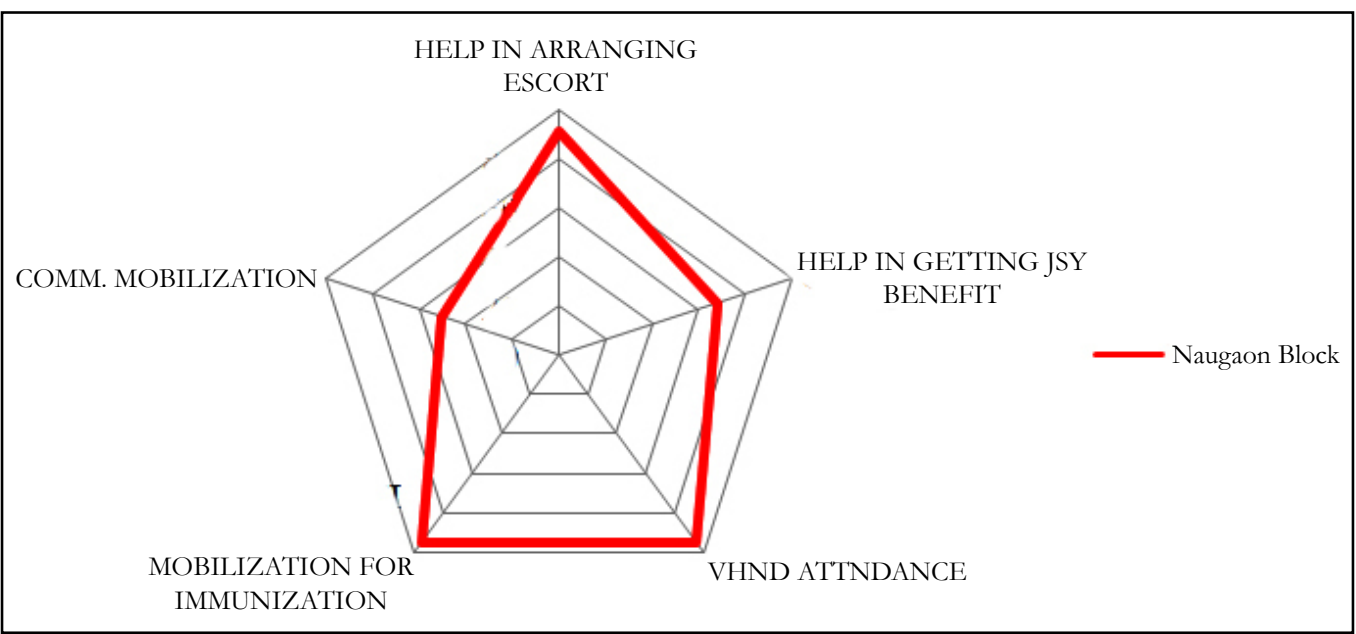

Figure 5. Perception of Beneficiary about ASHA.

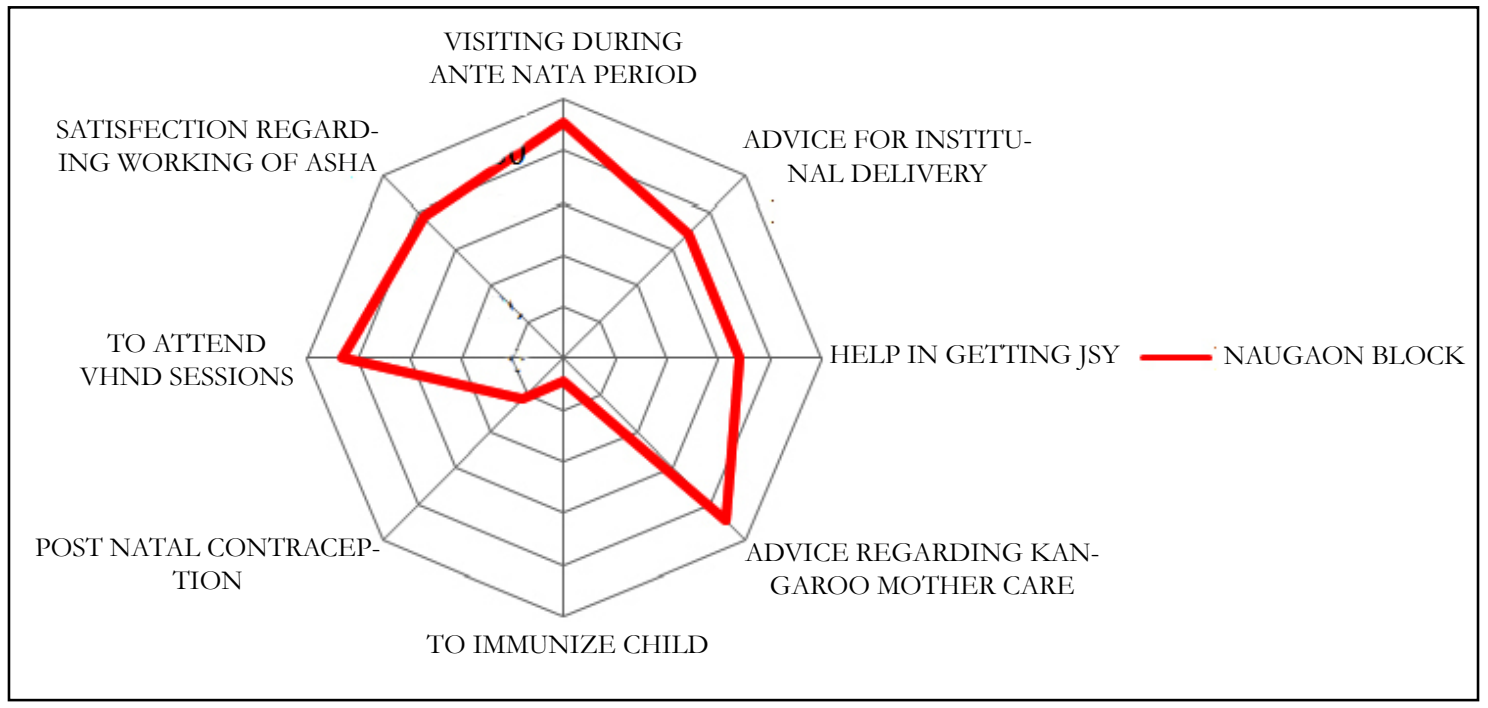

to services like the $A N C$ and blood tests (FGD, ASHA).

The Medical officers at $\mathrm{CHC}$ and Sector level have expressed their views on the following points about the ongoing ASHA program in their block during in depth interview. They have also opined about incentives of ASHA is a matter of concern.

Remote villages have poor roads and may take about a few hours to reach on foot. ASHAs maintain health records of the village; it saves time for the nurse in identification of pregnant women, children and sick people (IDI, CHC Doctor, Dr. N. C. Das (MS, O \& $G$ ) is working since last one year at Naugaon).

The amount of incentives needs to be biked and should be disbursed on a regular basis. The provision of giving annual rewards to the best performing ASHA at block level may be extended to number of $A S H A$ which will act 
as a strong motivating factor (IDI, Dr. Madhusmita Acharya, (BHMS) is working as MO/Ic. Alanabata sector).

Though application of this study finding are many its not without its shortcomings. This study has very small sample size (one sector only) making generalization of the findings difficult. Factors like population coverage distance from house hold, daily working hour and sincerity of ASHAs should have been considered. Qualitative tools like FDGs and IDI may have been used to ASHAs for rooting out various sociopolitical factors affecting their performance.

\section{Conclusions}

By and large, functionality of ASHAs in terms of carrying out tasks is reasonably high. Various factors like socioeconomic condition, job opportunity and knowledge seeking attitude are the driving force for ASHAs. As like various other research [10, 11, 14] in this study none of the ASHAs have the community serving attitude as stated by them. Many national studies across have pointed out that the lower educational status and lack of self motivation may be the factors affecting performance of ASHA [16, 21-23]. Hence during their selection besides educational eligibility other factors like attitude, judgment and critical thinking ability are to be incorporated. Regular on job training and periodic assessment should have been introduced as integral part of traning module. They should be treated as part of Health team of that district rather incentive based part time workers which will definitely boost their confidence. As like other international countries health system strengthening, basic Mental health knowledge, Non communicable risk factor identification should have been added to their work profile [5-7]. Basic health promotion and simple interventions like Sanitation, Hand Washing should be Promoted by ASHA $[27,28]$. The Regular periodic change in their existing curriculum and training should be the first priority in developing ASHA as competent health professionals should be done [29]. Incentive revision must be in place by a well coordinating committee is to be established, which may take the support of non-governmental organizations and civil society as needed.

\section{References}

[1]. Shukla A. National rural health mission--hope or disappointment? Indian J Public Health. 2005 Jul-Sep; 49(3):127-32. PubMed PMID: 16468275.

[2]. India. National Rural Health Mission. 6th Common review mission report New Delhi: National Rural Health Mission, Ministry of Health \& Family Welfare, Government of India. 2012;(1):36-38.

[3]. Lehmann U, Sanders D. World Health Organization. Community Health Workers: What Do We Know About Them? The State of the Evidence on Programmes, Activities, Costs an Impact on Health Outcomes of Using Community Health Workers. Geneva: HRH Global Resource Center. 2007 Jan;34.

[4]. Lewin S, Munabi-Babigumira S, Glenton C, Daniels K, Bosch-Capblanch $\mathrm{X}$, van Wyk BE, et al. Lay health workers in primary and community health care for maternal and child health and the management of infectious diseases. Cochrane Database Syst Rev. 2010 Mar 17;(3):CD004015. PubMed PMID: 20238326.

[5]. ZA Bhutta, ZS Lassi, G Pariyo, L Huicho. Global experience of community health workers for delivery of health related millennium development goals: a systematic review, country case studies, and recommendations for integration into national health systems. Global Health Workforce Alliance. 2010;1(249):61

[6]. Perry H, Zulliger R. How effective are community health workers? An Overview of Current Evidence with Recommendations for Strengthening Com- munity Health Worker Programs to Accelerate Progress in Achieving the Health-related Millennium Development Goals. Condensed version. The MDG Health Alliance. 2012 Sep. [22] p.

[7]. Paul VK, Sachdev HS, Mavalankar D, Ramachandran P, Sankar MJ, Bhandari $\mathrm{N}$ et al. Reproductive health, and child health and nutrition in India: meeting the challenge. Lancet. 2011 Jan 22; 377(9762):332-49. PubMed PMID: 21227494. PubMed Central PMCID: PMC3341742.

[8]. Ray SK. National Rural Health Mission opportunity for Indian public health association. Indian J Public Health. 2005 Jul-Sep; 49(3):171-4.PubMed PMID: 16468283

[9]. Tashakkori A, Teddlie C. Handbook of mixed methods in social and behavioral research.Thousand Oaks, CA: Sage Publications. 2003. 209-40p.

[10]. Mahyavanshi DK, Patel MG, Kartha G, Purani SK, Nagar SS. A cross sectional study of the knowledge, attitude and practice of ASHA workers regarding child health (under five years of age) in Surendranagar district. infection. Healthline Volume 2 Issue 2 July-December 2011.

[11]. Deoki Nandan, Y.D. Badgaiyan, V.K. Tiwari, H. Meitie, S. Menon. T. Bir et al. A Rapid Appraisal Of The Swasth Panchayat Scheme In The State Of Chhattisgarh. Health and Population. 2008. Vol. 31 (2), 106-112.

[12]. Walt G.Community health workers in national programmes: just another pair of hands? Milton Keynes: Open University. 1990.

[13]. India. Ministry of Health \& Family Welfare . Annual report to the people on health. New Delhi: Ministry of Health \& Family Welfare, Government of India. 2011;(1):67.

[14]. Srivastava DK, Prakash S, Adhish V, Nair KS, Gupta S, Nandan D. A study of interface of ASHA with the community and the service providers in Eastern Uttar Pradesh. Indian J Public Health. 2009 Jul-Sep; 53(3):133-6. PubMed PMID: 20108875.

[15]. National Health Systems Resource Centre ASHA-which way forward? Evaluation of ASHA Programme. New Delhi: National Health Systems Resource Centre: 2011.7-10.

[16]. Kalinga Centre for Social Development (KCDS). Rapid Appraisal of Functioning of Village Health and Sanitation Committee (VHSCs) under NRHM in Orissa (Sponsored by NIHFW and UNFPA). Bhubaneswar, Orissa. 2008.

[17]. Scott K, Shanker S. Tying their hands? Institutional obstacles to the success of the ASHA community health worker programme in rural north India. AIDS Care. 2010;22 Suppl 2:1606-12.PubMed PMID: 21161765.

[18]. Kumar S. Challenges of maternal mortality reduction and opportunities under National Rural Health Mission- a critical appraisal. Indian J Public Health. 2005 Jul-Sep;49(3):163-7.PubMed PMID: 16468281.

[19]. Haider, S, Vivek Adhish, Datta, U, Dhar, N, Menon, S, Nandan, Det al. A Rapid Appraisal of Sahiya (ASHA) in Jharkhand. Journal of Health and Population, 2008. Vol. 31 (2), pp.80-84.

[20]. N Bajpai, RH Dholakia. Improving the performance of accredited social health activists in India. (2011). NY: Columbia University (1):40-41.

[21]. India, Ministry of Health and Family Welfare, National Rural Health Mission, New Delhi. (2005). Guidelines on Accredited Social Health Activist. $11 \mathrm{p}$.

[22]. Prof. Deoki Nandan et al (2007-2008). A Rapid Appraisal Of Functioning Of ASHA Under NRHM In Cuttack, Orissa.

[23]. Ram Milan Prasot, JV Singh, AK Srivatava, Monika Agarwal. Factors influencing overall performance of ashas in mch care services under nrhm in rural lucknow.Indian J. Prev. Soc. Med. . 2012 Vol. 43 No.3.

[24]. Hema Bhatt. A rapid appraisal of functioning of ASHA under NRHM in Uttarakhand. 2012.

[25]. Uttekar BP, Uttekar V, Chakrawar BB, Sharma J, Shahane S. Assessment of Janani Suraksha Yojana in Uttar Pradesh. Centre for Operations Research and Training, Vadodara. 2008;2(8).

[26]. Fathima FN, Raju M, Varadharajan KS, Krishnamurthy A, Ananthkumar SR, Mony PK. Assessment of 'Accredited Social Health Activists'-A National Community Health Volunteer Scheme in Karnataka State, India. J Health Popul Nutr. 2015 Mar;33(1):137-45. PubMed PMID: 25995730, PubMed Central PMCID: PMC4438657.

[27]. National Health Systems Resource Centre. ASHA-which way forward? Evaluation of ASHA Programme. New Delhi: National Health Systems Resource Centre; 2011. pp. 7-10.

[28]. India. Registrar General of India (2012). Sample registration system. SRS Bullettin; 47:1-6.

[29]. India. Registrar General of India. Report on causes of death in India 20012003 (2009). New Delhi: Office of the Registrar General; (1): 2-6. 